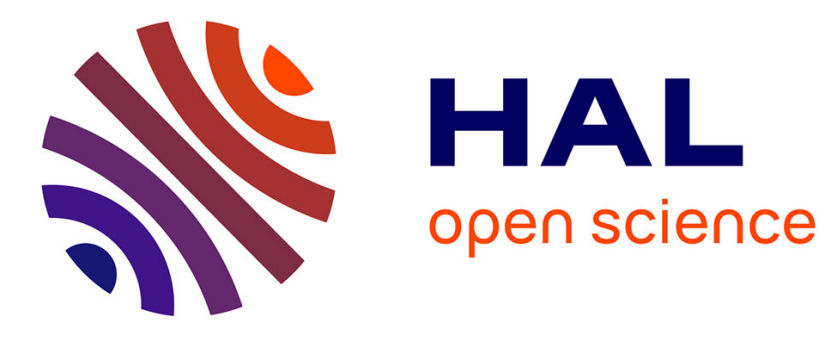

\title{
Characterization of Viral Rebounds on Dual Etravirine/Raltegravir Maintenance Therapy
}

Cathia Soulie, Lambert Assoumou, Basma Abdi, Sophie Sayon, Thuy Nguyen, Marc-Antoine Valantin, Lydie Beniguel, Virginie Ferre, Chakib Alloui, Brigitte Montes, et al.

\section{To cite this version:}

Cathia Soulie, Lambert Assoumou, Basma Abdi, Sophie Sayon, Thuy Nguyen, et al.. Characterization of Viral Rebounds on Dual Etravirine/Raltegravir Maintenance Therapy. Journal of Antimicrobial Chemotherapy, 2020, 75 (7), pp.1943-1949. 10.1093/jac/dkaa090 . hal-02988256

\section{HAL Id: hal-02988256 \\ https: / hal.sorbonne-universite.fr/hal-02988256}

Submitted on 4 Nov 2020

HAL is a multi-disciplinary open access archive for the deposit and dissemination of scientific research documents, whether they are published or not. The documents may come from teaching and research institutions in France or abroad, or from public or private research centers.
L'archive ouverte pluridisciplinaire HAL, est destinée au dépôt et à la diffusion de documents scientifiques de niveau recherche, publiés ou non, émanant des établissements d'enseignement et de recherche français ou étrangers, des laboratoires publics ou privés. 
5 Virginie FERRE ${ }^{4}$, Chakib ALLOUI ${ }^{5}$, Brigitte MONTES ${ }^{6}$, Véronique AVETTAND-FENOEL ${ }^{7}$, Constance DELAUGERRE ${ }^{8}$, Diane DESCAMPS $^{9}$,

6 Esteban MARTINEZ $^{10}$, Jacques REYNES ${ }^{11}$, Gilles PEYTAVIN ${ }^{12}$, Dominique COSTAGLIOLA ${ }^{2}$, Christine KATLAMA ${ }^{3}$, Vincent CALVEZ ${ }^{1}$,

7 Anne-Geneviève MARCELIN ${ }^{1}$ on behalf of the ETRAL ANRS 163 study group. $\uparrow$

$9{ }^{1}$ Sorbonne Université, INSERM, Institut Pierre Louis d'Epidémiologie et de Santé Publique, AP-HP, Hôpitaux Universitaires Pitié Salpêtrière -

10 Charles Foix, laboratoire de virologie, F75013, Paris, France

112 Sorbonne Université, INSERM, Institut Pierre Louis d'Epidémiologie et de Santé Publique, F75013, Paris, France

$12{ }^{3}$ Sorbonne Université, INSERM, Institut Pierre Louis d'Epidémiologie et de Santé Publique, AP-HP, Hôpitaux Universitaires Pitié Salpêtrière -

13 Service de maladies infectieuses, F75013, Paris, France

$14{ }^{4}$ Service de Virologie, CHU Nantes, France ; 
${ }^{5}$ AP-HP, Hôpital Avicennes, Service de Virologie, Bobigny, France ;

${ }^{6}$ Service de Virologie, CHU Montpellier, France ;

${ }^{7}$ AP-HP, Hôpital Necker, Service de Virologie, Institut Cochin - CNRS 8104 / INSERM U1016 / Université Paris Descartes, Paris, France ;

${ }^{8}$ AP-HP, Hôpital Saint Louis, Service de Virologie, Paris, France ;

${ }^{9}$ Sorbonne Paris Cité, INSERM, IAME, UMR 1137, AP-HP, Laboratoire de Virologie, Hôpital Bichat-Claude Bernard, Paris, France ;

${ }^{10}$ Infectious Diseases Unit Hospital Clinic, Barcelona, Spain;

${ }^{11}$ CHU Montpellier, Département de maladies infectieuses, Montpellier, France.

${ }^{12}$ AP-HP, Laboratoire de Pharmacologie-Toxicologie, Hôpital Bichat-Claude Bernard and IAME, UMR 1137, Sorbonne Paris Cité and INSERM,

$\dagger$ Members are listed in the acknowledgment section.

ClinicalTrials.gov: NCT02212379. 
EudraCT: 2014-000828-24.

28

CORRESPONDING AUTHOR

31 Dr Cathia Soulié, Laboratoire de Virologie-CERVI, Hôpital Pitié Salpêtrière 45-83 Bd de l'hôpital 75013 Paris, France. Phone: 33142175842.

32 Fax: 331421774 11. Email: cathia.soulie-ext@aphp.fr 


\section{ABSTRACT}

Background: ANRS-163 ETRAL trial, a switch study to etravirine $200 \mathrm{mg} /$ raltegravir $400 \mathrm{mg}$ twice daily regimen in 165 patients with HIV-1 infection, showed durable efficacy until week 96. The aim of this work was to investigate in details the virological rebounds (VR) defined as at least by one plasma HIV viral load (VL) $>50$ copies $/ \mathrm{mL}$

Methods: Quantification of HIV-DNA level was assessed at baseline, weeks 48 and $96(n=157)$. VLs were measured in seminal plasma at week $48(\mathrm{n}=26)$. Genotypic resistance testing by ultradeep sequencing (UDS) for reverse transcriptase (RT) and integrase regions were performed at baseline and at time of VR.

Results: In this study, 19 patients experienced VR with 2 patients with virological failure ( 2 consecutive VL $>50$ copies/mL). For the first patient with VF, UDS detected minority resistant variants only on RT (K103N: 9.6\%; Y181C: 4.9\%) at baseline. Some RT variants became dominant at VF (K101E: 86.3\%; Y181C: 100.0\%; G190A: 100.0\%) and others emerged on integrase (Y143C: 2.4\%; Q148R: 6.2\%; N155H: 18.8\%). For the second patient with VF, neither NNRTI nor INI mutations were detected at baseline and VF. Median HIV-DNA level was similar at baseline, weeks 48 and 96 (2.17, 2.06 and $2.11 \log _{10}$ copies $/ 10^{6}$ cells, respectively). Only one patient had a detectable seminal HIV VL (505 copies/mL).

Conclusions: The dual regimen etravirine/raltegravir as maintenance therapy was effective and the emergence of mutations in case of VF was similar to that seen in other dual regimen studies. No HIV-DNA level modification was evidenced through week 96. 


\section{BACKGROUND}

During long life therapy, alternative strategies are needed, particularly in HIV middle-aged patients to better manage comorbidities and polypharmacy. In the context of antiretroviral (ARV) toxicity, particularly NRTIs and PIs associated with long-term toxicity, a dual combination of etravirine/raltegravir (200/400 mg twice daily) was evaluated. The ANRS-163 ETRAL is a non-comparative study, aimed to evaluate over 96 weeks of treatment the capacity to maintain virological success of a dual raltegravir/etravirine twice a day regimen in HIV-1 infected patients, older than 45 years of age, with suppressed plasma viremia switching from a boosted PI-containing regimen (ClinicalTrial.gov: NCT02212379). The dual therapy raltegravir plus etravirine showed durable efficacy in the 165 virologically-suppressed patients, with benefits in metabolic and inflammatory parameters over 48 and 96 weeks, respectively. Only two patients had a virological failure (VF). ${ }^{1}$ Furthermore, there was no clinically significant pharmacokinetic interaction between etravirine and raltegravir and both etravirine and raltegravir plasma concentrations were adequate in most patients of this study. ${ }^{2}$

(1)
copies/mL in terms of : 1) resistance by Ultra Deep Sequencing (UDS), 2) HIV cell-associated HIV DNA changes and 3) seminal VL in the ETRAL ANRS-163 study. Furthermore, the potential factors associated with the VR were evaluated. 
PATIENTS AND METHODS

Study participants

The study population consisted in 165 HIV-1-infected adults enrolled and followed as previously described. ${ }^{1}$ The VF was defined as 2 consecutive measurements of HIV-1 pVL > 50 copies/mL ( $\mathrm{n}=2$ ) and VR as at least one VL >50 copies/mL ( $=19)$. A seminal sub-study was conducted in this trial in one center and semen samples were collected at week 48 (n=26). Furthermore, 17 patients without VR but with etravirine resistance mutations or $\mathrm{K} 103 \mathrm{~N}$ (etravirine sensitive) on the screening genotype were also studied as control for the HIV resistance analysis.

\section{Procedures}

The reverse transcriptase (RT) and integrase fragments were PCR-amplified with the «Agence Nationale de Recherche sur le Sida et les hépatites virales » protocols and Sanger sequencing was performed at screening (DNA) and in case of VF or viral blip (RNA). The resistance mutations were interpreted with the last version of ANRS algorithm (http://www.hivfrenchresistance.org/). 
The Illumina sequencing technology (MiSeq) was used to study HIV DNA RT and integrase resistance. The RT and integrase mutations

were analyzed with Smartgene ${ }^{\circledR}$ according to the lastest ANRS mutation list (cut-off 1\%) (http://www.hivfrenchresistance.org/) and by Genious (version 10.3.2; http://www.geneious.com). ${ }^{3}$

Quantification of pVL and seminal VL was performed using the AmpliPrep/COBAS TaqMan HIV-1 Test v2 or CAP/CTM TaqMan 48 HIV-1 V.2 (Roche Diagnostics, Basel, Switzerland), and the Abbot Realtime HIV-1 M2000rt (Abbott laboratories, Illinois, USA). Whole blood was collected at baseline, weeks 48 and 96, and cell associated HIV DNA was quantified as previously described (n=157). ${ }^{4}$

Plasma concentrations of etravirine and raltegravir, were determined by ultra-high performance liquid chromatography coupled with tandem mass spectrometry (UPLC-MS/MS; Waters Acquity UPLC-TQD, Milford, MA). ${ }^{5}$ The limit of quantification was $<5 \mathrm{ng} / \mathrm{ml}$ for all assays, and interpretation was based on the corresponding in vitro protein-adjusted 95\% inhibitory concentration (PBIC95) for wild-type (WT) HIV1: 116 $\mathrm{ng} / \mathrm{ml}$ for etravirine and $15 \mathrm{ng} / \mathrm{ml}$ for raltegravir. ${ }^{6}$

\section{Statistical analysis}

Variables were summarized with numbers and percentage for categorical variables and with median and range or interquartile range (IQR) for continuous variables. Kaplan-Meier estimator was used to estimate the proportion of participants with VR. Univariable and multivariable Cox regression model was used to identify factors associated with VR: age ( $\leq 60 \mathrm{y}$ and $>60 \mathrm{y})$, gender, ethnicity, CDC stage, transmission group, previous 
antiretroviral treatment (ART) intake (twice or once daily), previous ART (mono, dual or triple therapies), presence of tenofovir in the previous ART, duration of ART, baseline CD4 and CD8 cell counts, CD4/CD8 ratio, nadir CD4 cell count, time since HIV diagnosis, duration of suppressed viraemia, pre-ART pVL, baseline HIV cell-associated DNA, HIV-1 subtype, ETR resistance mutation, K103N mutation evidenced in historical or screening genotypes, presence of G to A mutation in DNA RT, tobacco consumption, alcohol consumption ( $\geq 2$ glasses/day), and presence of comorbidities. Variables with univariable P-value $<0.2$ were retained in the multivariable analysis. Changes in cell associated HIV-DNA were compared between baseline and week 48 and 96 using paired Wilcoxon test and the Mann-Whitney test was used for comparison of continuous variables between participants with and without VR. All reported P values are two-tailed, with significance set at 0.05 . Analyses were performed with SPSS statistics version 22.0 for Windows.

\section{RESULTS}

\section{Description of HIV resistance for patients with virological rebound by UDS}

For the first patient with VF (patient 1), minority HIV-1 variants on RT associated with etravirine resistance were detected (K103N: 9.6\%, Y181C: 4.9\%) at baseline with an increase of some variants at time of VF (K101E: 86.3\%, K103N: 12.5\%, K103S: 2.2\%, Y181C: 100.0\%, G190A:100.0\%). In addition, integrase resistant variants not detected at baseline emerged at VF (T66I: 65.4\%, Y143C: $2.4 \%$, Q148R: 6.2\%, 
N155H: 18.8\%), leading to raltegravir resistance. The presence of these resistant variants was associated with HIV resistance to all NNRTIs and integrase inhibitors. The raltegravir $(132 \mathrm{ng} / \mathrm{mL})$ and etravirine $(547 \mathrm{ng} / \mathrm{mL})$ plasma concentrations 12 hours after the last drug intakes were adequate at the time of failure (table 1).

With regards to the second patient with VF (patient 2), there was no detection at baseline of resistant variants in the RT and integrase genes using UDS DNA genotype despite past etravirine associated resistance mutations (K103N, E138A and V106I) that were missed at screening. At time of VF, no mutation to NNRTIs and integrase inhibitors was detected by Sanger and UDS (table 1$)$. The raltegravir (1,418 ng/ml) and etravirine (505 ng/mL) plasma concentrations were also adequate (table 1).

Along the study duration, 17 patients experienced at least one $\mathrm{VL}>50$ copies/mL: 10 occured between week 4 and week 48 , and 8 between week 64 and 96 (median 106 copies/mL; range 57-543) (table 1). The raltegravir and etravirine concentrations were in median for these 17 patients 331 and $488 \mathrm{ng} / \mathrm{mL}$, respectively. Due to the low level of pVL, only 5 RT and 6 integrase genes (7 patients) were successfully amplified by Sanger sequencing with no mutation leading to etravirine or raltegravir resistance. The E138K mutation was detected on integrase gene leading to elvitegravir resistance in one patient with a pVL at 163 copies/mL (patient 14). The pVL were so low at VL rebound that only 1 RT (patient 8) and 2 integrase (patient 3 and 8) genes could be amplified for UDS with no resistance mutations for NNRTIs and a S147G in integrase gene (1.1\% for the patient 8) (table 1). To better understand the potential implications of minority variants in the viral blips in the ETRAL trial, the RT and integrase genes were also evaluated at baseline for these 17 patients by UDS in DNA. At baseline, 6 RT (patients 3, 4, 7, 10, 11 and 14) and 8 integrase genes (patients 3, 4, 6, 7, 8, 10,11 and 14) could be amplified. Considering etravirine resistance associated mutations, two minority 
variants are reported: $\mathrm{E} 138 \mathrm{~K}(8.6 \%$, patient 7$), \mathrm{E} 138 \mathrm{G}(1.5 \%$, patient 11$)$. Only the patient 4 exhibits a resistance variant associated with raltegravir resistance (G118R: 1.4\%) (table 1).

To evaluate the impact of the minority resistant variants in a context of VR but also in success, UDS was realized for RT of 17 patients with no VR over the 96 weeks of follow-up, with baseline etravirine resistance mutations detected by Sanger sequencing. Among them, 15 harbored viruses with etravirine resistance mutations at baseline evidenced by UDS confirming the screening Sanger genotypes, and leading to etravirine resistance (R) for 2 patients and to intermediate resistance (I) for 2 others, respectively: V90I (7.2\%), K101R (12.1\%), V179I (12.6\%) [R, n=1]; E138K (1.2\%) [R, n=1]; A98G (51.6\%), K101R (10.3\%) [I, n=1]; V90I (76.8\%), E138A (2.5\%) [I, n=1].

Evaluation of HIV-DNA levels

No statistical change of HIV-DNA level was observed between baseline (median $2.17 \log _{10}$ copies/10 cells), and week 48 (2.06 log 10 copies $/ 10^{6}$ cells; $\left.\mathrm{p}=0.054\right)$ or week $96\left(2.11 \log _{10}\right.$ copies $/ 10^{6}$ cells; $\left.\mathrm{p}=0.750\right)$. Furthermore, there was no impact of HIV-DNA level at baseline on the occurrence of VR defined as at least one $\mathrm{pVL}>50$ copies/mL (2.29 $\log _{10}$ copies $/ 10^{6}$ cells versus $2.14 \log _{10}$ copies/10 cells for patients with or without VR, respectively; $\mathrm{p}=0.839$ ). 


\section{Seminal substudy}

As the control of HIV VL in compartments in the context of dual therapy was a concern, HIV VL was measured on 26 seminal plasma at week 48. All these VL were < 100 copies/mL, except for one patient with a seminal VL at 505 copies/mL (raltegravir concentration: $560 \mathrm{ng} / \mathrm{mL}$; etravirine concentrations: $175 \mathrm{ng} / \mathrm{mL})$ with a corresponding plasma $\mathrm{VL}<50$ copies $/ \mathrm{mL}$. This patient experienced a blip (75 copies/mL) at week 96 in plasma (patient 18, table 1). The Sanger genotype revealed no mutation in integrase gene, and unfortunately the RT gene was not successfully amplified. Overall, the raltegravir and etravirine concentrations were 638 and $119 \mathrm{ng} / \mathrm{mL}$ in seminal plasma in median, respectively.

\section{Factors associated with the virological rebound}

Six factors were retained for the multivariable analysis: presence of at least one etravirine resistance mutation in DNA Sanger at baseline or in historical RNA ( $\mathrm{p}=0.117$ ), presence of $\mathrm{K} 103 \mathrm{~N}$ resistance mutation in DNA Sanger at baseline or in historical RNA ( $\mathrm{p}=0.077$ ), tenofovir disoproxil fumarate in the previous antiretroviral treatment $(\mathrm{p}=0.018)$, duration of $\mathrm{pVL}<50$ copies $/ \mathrm{mL}(<$ or $>4$ years, $\mathrm{p}=0.059)$, age $(<$ or $>60$ years, $p=0.035)$ and consumption of alcohol $(\geq 2$ glasses/day) $(\mathrm{p}=0.008)$ (table 2$)$. The multivariable analysis showed that the risk of VR was independently associated with age and alcohol consumption. The risk was 3.7 times higher (95\%CI, 1.4-10.1) in patients with >60 years old and 11.3 times higher (95\%CI, 1.5-85.1) when they consumed $\geq 2$ glasses of alcohol per day. 
The dual maintenance therapy with raltegravir/etravirine 400/200 mg twice daily was highly effective in patients over 45 years of age over 96 weeks switching from a PI-containing regimen regimen. Only 2 individuals out of 165 experienced virological failure. Seventeen individuals experienced blips with subsequent HIV pVL $<50$ copies/mL without treatment changes. The HIV DNA level did not change during the 96 weeks of follow-up.

For the first patient with VF, the Sanger sequencing evidenced NNRTI mutations at failure (K101E, Y181C and G190A) and some of them (K103N and Y181C) were already detected at baseline by UDS. All etravirine mutations detected by Sanger sequencing at failure were also shown by UDS as majority variants. To note, the K103N detected at baseline and not associated with etravirine resistance remained as minority variants. Furthermore, some integrase resistance mutations were evidenced by UDS and not previously detected by Sanger sequencing. The use of UDS in this case was informative to explain the VF as the NNRTIs resistance associated mutations were found at baseline and the integrase resistance associated mutations were revealed at failure while they were not evidenced by Sanger sequencing. This result was in line with previous studies showing the input of UDS over Sanger sequencing for detecting resistance for the antiretroviral class of NNRTIs. ${ }^{7,8}$

For the second patient with VF, some NNRTIs mutations (K103N, E138A and V106I) were retrospectively evidenced in the medical history of the patient after the VF, and neither Sanger sequencing nor UDS detected these mutations at baseline and VF. ${ }^{1}$ These results illustrated another issue concerning the treatment of HIV patient with undetectable pVL, the assessment of resistance and the impact of archived resistance. Indeed, 
it is currently admitted that Sanger RNA genotyping during previous periods of VF remains the gold standard for documenting resistance mutations and for the monitoring of future treatments. ${ }^{9,10}$ However, in clinical practice and in this study, the HIV DNA genotyping was also performed. The impact of mutations (evidenced in historical RNA or DNA at screening) on the ARV treatment prescribed many years later and after many years of undetectable pVL is not well documented. It has been shown recently that there is a clear trend towards clearance of archived resistance associated mutations to RT inhibitors in cell-associated HIV-1 DNA after a long period of virological control, free from therapeutic selective pressure on these mutations. ${ }^{11}$

In the present study, the number of patients with VF was low and 1/2 showed the emergence of resistance mutations to NNRTI and INI. This result could be compared to that was observed in other dual regimen based on NNRTI and INI. In FLAIR study (cabotegravir/rilpivirine), $3 / 6$ patients (50\%) had HIV-1 with both resistance associated mutations in RT and integrase genes leading to resistance. ${ }^{12}$ In the SWORD-1 and -2 studies (dolutegravir/rilpivirine), 3/10 patients presented emerging NNRTIs resistance mutations (30\%) at W100, but with no INI resistance mutations. ${ }^{13}$ The combination of dual NNRTI plus INI should be taken into account considering the genetic barrier to resistance of each antiretroviral.

It is very reassuring to show that there was no variation of HIV DNA VL in blood during the 2 years of follow-up on the etravirine/raltegravir regimen arguing for the absence of an eventual replenishment of the reservoirs. This was in accordance with data obtained from other dual or monotherapy studies showing no difference versus triple therapy. ${ }^{14-16}$ 

mg) twice daily: age ( $>60$ years) and alcohol consumption ( $\geq 2$ glasses/day). Nevertheless, given the low number of events ( $n=19)$, these results should be taken with cautious. Furthermore, the confidence intervals was too wide for alcohol consumption. Although the alcohol consumption is one of the main factors associated with non-adherence, it should to be taken with cautious in the context of the ANRS-165 ETRAL study as the total etravirine and raltegravir plasma concentrations were adequate in most patients, favoring virologic efficacy and confirming good treatment adherence $(>95 \%) .^{2,17}$

In conclusion, the dual regimen raltegravir/etravirine represents an effective option for patients in a context of suppressed viraemia. The emergence of mutations in case of VF in this trial was similar to that seen in other NNRTI plus INI dual regimen studies. In addition, this dual maintenance therapy did not modify HIV DNA VL through week 96. This strategy remains to be evaluated in a context of once daily intake. 
ETRAL investigators : Professor Louis Bernard (Hôpital Bretonneau, Tours), Dr Julie Bottero (Hôpital Jean Verdier, Bondy), Professor Olivier Saint André, Bordeaux), Dr Alissa Naqvi (Hôpital l'Archet, Nice), Dr Daniel Podzamczer (Hospital de Bellvitge, Barcelona), Dr Isabelle PoizotChauliac, Montpellier), Professor Dominique Salmon-Céron (Hôpital Cochin, Paris), Dr Anne Simon (Hôpital Pitié-Salpêtrière, Paris), Dr MarcYazdanpanah (Hôpital Bichat-Claude Bernard, Paris). 
FUNDING

207 The ANRS 163 ETRAL study was funded by the French National Institute for Health and Medical Research (INSERM)-French National Agency

208 for Research on AIDS and Viral Hepatitis (ANRS); the ETRAL study was also supported by MSD and Janssen.

\section{TRANSPARENCY DECLARATION}

210 All other authors: none to declare. 


\section{REFERENCES}

1. Katlama C, Assoumou L, Valantin M-A, et al. Dual therapy combining raltegravir with etravirine maintains a high level of viral suppression over 96 weeks in long-term experienced HIV-infected individuals over 45 years on a PI-based regimen: results from the Phase II ANRS 163 ETRAL study. J Antimicrob Chemother 2019; 74 (9): 2742-2751.

2. Lê M, Valantin M, Assoumou L, et al. Lack of a Clinically Significant Pharmacokinetic Interaction between Etravirine and Raltegravir Using an Original Approach Based on Drug Metabolism, Protein Binding, and Penetration in Seminal Fluid: A Pharmacokinetic Substudy of the ANRS163 ETRAL Study. Pharmacotherapy 2019; 39 (4): 514-520.

3. Nguyen T, Fofana DB, Lê MP, et al. Prevalence and clinical impact of minority resistant variants in patients failing an integrase inhibitor-based regimen by ultra-deep sequencing. J Antimicrob Chemother 2018; 73: 2485-92.

4. Avettand-Fènoël V, Chaix M-L, Blanche S, et al. LTR real-time PCR for HIV-1 DNA quantitation in blood cells for early diagnosis in infants born to seropositive mothers treated in HAART area (ANRS CO 01). J Med Virol 2009; 81: 217-23.

5. Jung BH, Rezk NL, Bridges AS, et al. Simultaneous determination of 17 antiretroviral drugs in human plasma for quantitative analysis with liquid chromatography-tandem mass spectrometry. Biomed Chromatogr 2007; 21: 1095-104.

6. Markowitz M, Morales-Ramirez JO, Nguyen B-Y, et al. Antiretroviral activity, pharmacokinetics, and tolerability of MK-0518, a novel inhibitor of HIV-1 integrase, dosed as monotherapy for 10 days in treatment-naive HIV-1-infected individuals. J Acquir Immune Defic Syndr 2006; 43: 50915.

7. Todesco E, Rodriguez C, Morand-Joubert L, et al. Improved detection of resistance at failure to a tenofovir, emtricitabine and efavirenz regimen by ultradeep sequencing. J Antimicrob Chemother 2015; 70: 1503-6.

8. Vandenhende M-A, Bellecave P, Recordon-Pinson P, et al. Prevalence and evolution of low frequency HIV drug resistance mutations detected by ultra deep sequencing in patients experiencing first line antiretroviral therapy failure. PLoS ONE 2014; 9: e86771.

9. Wirden M, Soulie C, Valantin M, et al. Historical HIV-RNA resistance test results are more informative than proviral DNA genotyping in cases of suppressed or residual viraemia. J Antimicrob Chemother 2011; 66: 709-12. 
10. Armenia D, Zaccarelli M, Borghi V, et al. Resistance detected in PBMCs predicts virological rebound in HIV-1 suppressed patients switching treatment. J Clin Virol 2018; 104: 61-4.

11. Nouchi A, Nguyen T, Valantin M, et al. Dynamics of drug resistance-associated mutations in HIV-1 DNA reverse transcriptase sequence during effective ART. J Antimicrob Chemother 2018; 73: 2141-6.

12. Orkin C, Arasteh K, Hernandez-Mora M, et al. Long-acting Cabotegravir+ Rilpivirine for HIV maintenance: FLAIR week 48 results. In CROI: Seattle, Washington, USA, 2019.

13. Aboud M, Orkin C, Podzamczer D, et al. Efficacy and safety of dolutegravir-rilpivirine for maintenance of virological suppression in adults with HIV-1: 100-week data from the randomised, open-label, phase 3 SWORD-1 and SWORD-2 studies. Lancet HIV 2019 ; 6: e576-87.

14. Lambert-Niclot S, Flandre P, Valantin M, et al. Similar evolution of cellular HIV-1 DNA level in darunavir/ritonavir monotherapy versus triple therapy in MONOI-ANRS136 trial over 96 weeks. PLoS ONE 2012; 7: e41390.

15. Lombardi F, Belmonti S, Quiros-Roldan E, et al. Evolution of blood-associated HIV-1 DNA levels after 48 weeks of switching to atazanavir/ritonavir+lamivudine dual therapy versus continuing triple therapy in the randomized AtLaS-M trial. J Antimicrob Chemother 2017; 72: $2055-9$.

16. Avettand-Fenoel V, Bouteloup V, Mélard A, et al. Higher HIV-1 DNA associated with lower gains in CD4 cell count among patients with advanced therapeutic failure receiving optimized treatment (ANRS 123--ETOILE). J Antimicrob Chemother 2010; 65: $2212-4$.

17. Detsis M, Tsioutis C, Karageorgos SA, Sideroglou T, Hatzakis A, Mylonakis E. Factors Associated with HIV Testing and HIV Treatment Adherence: A Systematic Review. Curr Pharm Des 2017; 23: 2568-78. 


\begin{tabular}{|c|c|c|c|c|c|c|c|c|c|}
\hline \multirow[b]{2}{*}{ Interpretation } & \multicolumn{3}{|c|}{$\begin{array}{l}\text { VL and drug } \\
\text { concentrations }\end{array}$} & \multicolumn{3}{|c|}{ Sanger } & \multicolumn{3}{|c|}{ UDS } \\
\hline & $\begin{array}{c}\mathrm{VL} \\
\text { (copies } / \mathrm{mL} \text { ) }\end{array}$ & $\begin{array}{l}\text { RAL C12h } \\
\text { (ng/mL) }\end{array}$ & $\begin{array}{l}\text { ETR C12h } \\
\text { (ng/mL) }\end{array}$ & NNRTI & Integrase & Interpretation & NNRTI & Integrase & Interpretation \\
\hline $\begin{array}{l}\text { ETR R } \\
\text { RAL S }\end{array}$ & $\begin{array}{l}11607 \text { (W24) } \\
18472 \text { (CTR) }\end{array}$ & $\begin{array}{c}132 \text { (W24) } \\
94 \text { (CTR) }\end{array}$ & $\begin{array}{l}547 \text { (W24) } \\
584 \text { (CTR) }\end{array}$ & $\begin{array}{l}\text { K101E } \\
\text { Y181C } \\
\text { G190A }\end{array}$ & T66I & $\begin{array}{l}\text { ETR R } \\
\text { RAL S }\end{array}$ & $\begin{array}{l}\text { K101E: } 86.3 \%, \\
\text { K103N: } 12.5 \%, \\
\text { K103S: } 2.2 \%, \\
\text { Y181C: } 100.0 \%, \\
\text { G190A: } 100.0 \%\end{array}$ & $\begin{array}{l}\text { T66l: 65.4\%, } \\
\text { Y143C: } 2.4 \%, \\
\text { Q148R: } 6.2 \%, \\
\text { N155H: } 18.8 \%\end{array}$ & $\begin{array}{l}\text { ETR R } \\
\text { RAL R }\end{array}$ \\
\hline $\begin{array}{l}\text { ETR S } \\
\text { RALS }\end{array}$ & $\begin{array}{l}69 \text { (W64) } \\
75 \text { (CTR) }\end{array}$ & 1418 (VF) & $505(V F)$ & No mutation & No mutation & $\begin{array}{l}\text { ETR S } \\
\text { RALS }\end{array}$ & No mutation & No mutation & $\begin{array}{l}\text { ETR S } \\
\text { RALS }\end{array}$ \\
\hline $\begin{array}{l}\text { ETR S } \\
\text { RAL } S\end{array}$ & $\begin{array}{l}116 \text { (W4) } \\
<20 \text { (CTR) }\end{array}$ & $210(W 4)$ & 369 (W4) & No mutation & No mutation & $\begin{array}{l}\text { ETR S } \\
\text { RALS }\end{array}$ & NA & No mutation & RAL $S$ \\
\hline $\begin{array}{l}\text { ETR S } \\
\text { RAL R }\end{array}$ & $\begin{array}{l}61 \text { (W4) } \\
<20 \text { (CTR) }\end{array}$ & 334 (W4) & 574 (W4) & No mutation & NA & ETR S & NA & NA & \\
\hline & 59 (W4) & 328 (W4) & 328 (W4) & NA & NA & & NA & NA & \\
\hline
\end{tabular}




\begin{tabular}{|c|c|c|c|c|c|c|c|c|c|}
\hline & 26 (CTR) & & & & & & & & \\
\hline RALS & $\begin{array}{l}58 \text { (W12) } \\
<20 \text { (CTR) }\end{array}$ & 40 (W12) & 249 (W12) & NA & NA & & NA & NA & \\
\hline $\begin{array}{l}\text { ETR R } \\
\text { RALS }\end{array}$ & $\begin{array}{l}160 \text { (W12) } \\
<20 \text { (CTR) }\end{array}$ & 2,253 (W12) & 697 (W12) & No mutation & NA & ETR $S$ & NA & NA & \\
\hline \multirow[t]{2}{*}{ RALS } & $\begin{array}{l}95 \text { (W24) } \\
<20 \text { (CTR) }\end{array}$ & 157 (W24) & 519 (W24) & No mutation & No mutation & $\begin{array}{l}\text { ETR S } \\
\text { RAL S }\end{array}$ & No mutation & S147G (1.1\%) & $\begin{array}{l}\text { ETR S } \\
\text { RALS }\end{array}$ \\
\hline & $\begin{array}{l}60 \text { (W36) } \\
<20 \text { (CTR) }\end{array}$ & 182 (W36) & 441 (W36) & NA & NA & & NA & NA & \\
\hline $\begin{array}{l}\text { ETR S } \\
\text { RALS }\end{array}$ & $\begin{array}{l}296 \text { (W48) } \\
<20 \text { (CTR) }\end{array}$ & $\begin{array}{l}108 \text { (W24) } \\
\text { NA (W48) }\end{array}$ & $\begin{array}{l}146 \text { (W24) } \\
\text { NA (W48) }\end{array}$ & NA & NA & & NA & NA & \\
\hline \multirow[t]{3}{*}{$\begin{array}{l}\text { ETR I } \\
\text { RALS }\end{array}$} & $\begin{array}{l}543 \text { (W48) } \\
<20 \text { (CTR) }\end{array}$ & 1,599 (W48) & 172 (W48) & NA & No mutation & RAL $S$ & NA & NA & \\
\hline & $\begin{array}{l}127 \text { (W48) } \\
49 \text { (W64) }\end{array}$ & 42 (W48) & 487 (W48) & NA & NA & & NA & NA & \\
\hline & $\begin{array}{l}57 \text { (W64) } \\
<20 \text { (CTR) }\end{array}$ & 853 (w64) & 704 (w64) & NA & NA & & NA & NA & \\
\hline
\end{tabular}




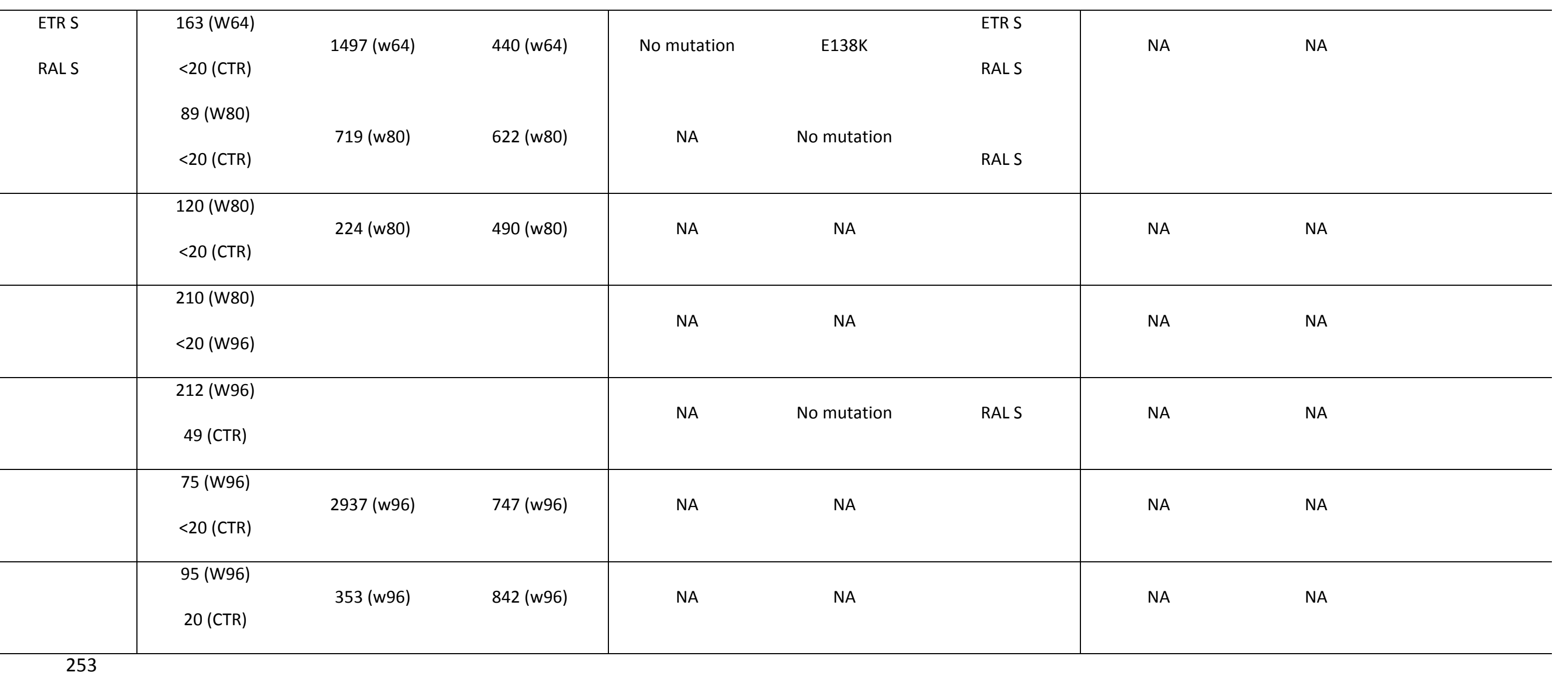




\begin{tabular}{|c|c|c|c|c|c|c|}
\hline & \multirow{2}{*}{\multicolumn{2}{|c|}{$\begin{array}{l}\text { Patients who experienced a } \\
\text { pVL }>50 \text { copies } / \mathrm{mL}\end{array}$}} & \multicolumn{4}{|c|}{$\begin{array}{c}\text { Univariate and Multivariable Cox proportional hazards } \\
\text { model }\end{array}$} \\
\hline & & & \multicolumn{2}{|c|}{ Univariate analysis } & \multicolumn{2}{|c|}{ Multivariable analysis } \\
\hline & No & Yes & HR (95\% CI) & p-value & HR (95\% CI) & p-value \\
\hline Age, years, median (IQR) & $52(48-57)$ & $54(48-64)$ & $1.03(0.99-1.08)$ & 0.065 & & \\
\hline \multicolumn{7}{|l|}{ Age group, n (\%) } \\
\hline - $\quad<60$ years & $123(91 \%)$ & $12(9 \%)$ & 1 & & 1 & \\
\hline - $\quad>60$ years & $23(77 \%)$ & $7(23 \%)$ & $2.72(1.07-6.91)$ & 0.035 & $3.72(1.37-10.12)$ & 0.010 \\
\hline \multicolumn{7}{|l|}{ Gender-sex, n (\%) } \\
\hline - $\quad$ Male & $102(87 \%)$ & $15(13 \%)$ & 1 & & & \\
\hline - $\quad$ Female & $44(92 \%)$ & $4(8 \%)$ & $0.62(0.20-1.85)$ & 0.615 & & \\
\hline Origin-ethnicity, n (\%) & & & & 0.669 & & \\
\hline • Caucasian & $111(90 \%)$ & $13(10 \%)$ & 1 & & & \\
\hline - Sub-saharan Africa & $21(88 \%)$ & $3(13 \%)$ & $1.16(0.33-4.06)$ & 0.821 & & \\
\hline - $\quad$ Other & $14(82 \%)$ & $3(18 \%)$ & $1.77(0.51-6.23)$ & 0.371 & & \\
\hline CDC stage, $\mathrm{n}(\%)$ & & & & 0.673 & & \\
\hline - $\mathrm{A}$ & $87(89 \%)$ & $11(11 \%)$ & 1 & & & \\
\hline - $\mathrm{B}$ & $26(84 \%)$ & $5(16 \%)$ & $1.44(0.50-4.15)$ & 0.498 & & \\
\hline - $\mathrm{C}$ & $33(92 \%)$ & $3(8 \%)$ & $0.78(0.22-2.80)$ & 0.702 & & \\
\hline Transmission group, $\mathrm{n}(\%)$ & & & & 0.232 & & \\
\hline • Men who sex with men & $55(83 \%)$ & $11(17 \%)$ & 1 & & & \\
\hline - Heterosexual & $66(92 \%)$ & $6(8 \%)$ & $0.46(0.17-1.24)$ & 0.124 & & \\
\hline - $\quad$ Other & $25(93 \%)$ & $2(7 \%)$ & $0.28(0.10-1.96)$ & 0.279 & & \\
\hline \multicolumn{7}{|l|}{ Previous antiretroviral treatment intake } \\
\hline - $\quad$ Twice daily & $41(91 \%)$ & $4(9 \%)$ & 1 & & & \\
\hline - $\quad$ Once daily & $105(88 \%)$ & $15(12 \%)$ & $1.37(0.46-4.14)$ & 0.573 & & \\
\hline
\end{tabular}


Previous antiretroviral treatment

- Monotherapy

$34(97 \%)$

$1(3 \%)$

1

0.251

- Triple therapy or more

$16(89 \%)$

$2(11 \%) \quad 4.08(0.37-45.00)$

$96(86 \%)$

$16(14 \%) \quad 5.26(0.70-39.68)$

0.107

Presence of TDF in previous antiretroviral treatment

$$
\begin{array}{ll}
\text { - } & \text { No } \\
\text { - } & \text { Yes }
\end{array}
$$

Duration of antiretroviral treatment, years

Baseline CD4 cell count, cells $/ \mathrm{mm}^{3}$

Baseline CD8 cell count, cells $/ \mathrm{mm}^{3}$

\section{CD4/CD8 ratio}

Nadir CD4 cell count, cells $/ \mathrm{mm}^{3}$

Time since HIV diagnosis, years

Duration of suppressed viraemia, years

Duration of suppressed viraemia,

$$
\begin{aligned}
& \text { - } \quad<4 \text { years } \\
& \text { - } \quad>4 \text { years }
\end{aligned}
$$

Pre-ART plasma viral load, $\log _{10}$ copies/mL

Baseline HIV DNA VL, log copies $/ 10^{6}$ cells Subtype, n (\%)

$$
\begin{array}{ll}
\text { - } & \text { B } \\
\text { - } & \text { CRF02_AG } \\
\text { - Other }
\end{array}
$$

ETR resistance mutation

$$
\text { - No }
$$

- At least one

K103N resistance mutation

$$
90(94 \%) \quad 6(6 \%)
$$

$56(81 \%)$

$13(19 \%)$

$3.22(1.22-8.48)$

$1.03(0.95-1.11)$

17 (11-19)

18 (13-19)

$1.00(0.99-1.00)$

701 (530-904)

$704(548-880)$

$686(562-979) \quad 1.00(0.99-1.00)$

718 (545-996)

$0.97(0.67-$
$1.27)$

$0.88(0.39-2.00)$

$0.93(0.66-1.24)$

208 (89-283)

$20(12-24)$

$244(122-301) \quad 1.00(0.99-1.00)$

19 (14-25)

$5(2-8)$

$1.03(0.97-1.10)$

$0.89(0.77-1.02)$

$39(81 \%)$

$9(19 \%)$

$9(8 \%)$

$5.10(4.56-$

4.78 (4.22-5.49)

$5.10(4.56)$
5.

2.14 (1.82-2.47)

2.29 (1.86-

2.40)

1

0.41 (0.16-1.04)

$1.32(0.68-2.58)$

$1.30(0.41-4.17)$

$68(91 \%)$

$7(9 \%)$

$2(100 \%)$

$0(0 \%)$

15 (94\%)

$1(6 \%)$

1

$0.62(0.08-5.06)$

$132(90 \%)$

$15(10 \%)$

$14(78 \%)$

$4(22 \%)$

$2.41(0.80-7.27)$
$0.0182 .61(0.92-7.45) \quad 0.072$

0.516

1.000

0.837

0.756

0.623

0.339

0.085

0.059 $0.47(0.18-1.26) \quad 0.133$

0.417

0.657

0.906

0.990

0.657

$0.1172 .04(0.60-6.95) \quad 0.256$ 
- No

- Yes

G-to-A mutations number

Tobacco consumption

- $\quad$ No smoker

- Former smoker

- Active smoker

Alcohol consumption

day)

- Never

- Occasional/regular ( $\geq 2$ glasses per

$134(90 \%)$

$15(10 \%)$

$12(75 \%)$

9 (6-12)

$4(25 \%)$

1

$10(8-14)$

$2.71(0.90-8.17)$

$1.004(0.955-1.057)$

$65(88 \%)$

$29(94 \%)$

$52(87 \%)$

$9(12 \%)$

$2(6 \%)$

$8(13 \%)$

$.56(0.12-2.59)$

$1.18(0.46-3.07)$

$69(99 \%)$

$77(81 \%)$

$1(1 \%)$

$18(19 \%)$

1

$5.14(2.02-113.44)$

0.008

(11\%)

$9(11 \%)$

$10(12 \%)$

- No

$71(89 \%)$

$75(88 \%)$

$.02(0.42-2.51)$

0.964
1

$\mathbf{0 . 0 7 7}$

0.867

0.639

0.459

0.729

258

Table 2: Univariate and Multivariable Cox proportional hazards model of factors predictive of the occurrence of plasma virological rebound ( $\mathrm{pVL}>50 \mathrm{copies} / \mathrm{mL}$ ) with etravirine/raltegravir therapy among HIV-infected patients. Variables with univariate p-values $<0.2$ were retained for the multivariable analysis.

261 Continuous variables are described as median with interquartile range and categorical variables with number and percentage. 